\title{
Climatologists under pressure
}

\author{
Stolen e-mails have revealed no scientific conspiracy, but do highlight ways in which climate researchers \\ could be better supported in the face of public scrutiny.
}

$\mathrm{T}$ he e-mail archives stolen last month from the Climatic Research Unit at the University of East Anglia (UEA), UK, have been greeted by the climate-change-denialist fringe as a propaganda windfall (see page 551). To these denialists, the scientists' scathing remarks about certain controversial palaeoclimate reconstructions qualify as the proverbial 'smoking gun': proof that mainstream climate researchers have systematically conspired to suppress evidence contradicting their doctrine that humans are warming the globe.

This paranoid interpretation would be laughable were it not for the fact that obstructionist politicians in the US Senate will probably use it next year as an excuse to stiffen their opposition to the country's much needed climate bill. Nothing in the e-mails undermines the scientific case that global warming is real - or that human activities are almost certainly the cause. That case is supported by multiple, robust lines of evidence, including several that are completely independent of the climate reconstructions debated in the e-mails.

First, Earth's cryosphere is changing as one would expect in a warming climate. These changes include glacier retreat, thinning and areal reduction of Arctic sea ice, reductions in permafrost and accelerated loss of mass from the Greenland and Antarctic ice sheets. Second, the global sea level is rising. The rise is caused in part by water pouring in from melting glaciers and ice sheets, but also by thermal expansion as the oceans warm. Third, decades of biological data on blooming dates and the like suggest that spring is arriving earlier each year.

Denialists often maintain that these changes are just a symptom of natural climate variability. But when climate modellers test this assertion by running their simulations with greenhouse gases such as carbon dioxide held fixed, the results bear little resemblance to the observed warming. The strong implication is that increased greenhouse-gas emissions have played an important part in recent warming, meaning that curbing the world's voracious appetite for carbon is essential (see pages 568 and 570).

\section{Mail trail}

A fair reading of the e-mails reveals nothing to support the denialists' conspiracy theories. In one of the more controversial exchanges, UEA scientists sharply criticized the quality of two papers that question the uniqueness of recent global warming (S. McIntyre and R. McKitrick Energy Environ. 14, 751-771; 2003 and W. Soon and S. Baliunas Clim. Res. 23, 89-110; 2003) and vowed to keep at least the first paper out of the upcoming Fourth Assessment Report of the Intergovernmental Panel on Climate Change (IPCC). Whatever the e-mail authors may have said to one another in (supposed) privacy, however, what matters is how they acted. And the fact is that, in the end, neither they nor the IPCC suppressed anything: when the assessment report was published in 2007 it referenced and discussed both papers.

If there are benefits to the e-mail theft, one is to highlight yet again the harassment that denialists inflict on some climate-change researchers, often in the form of endless, time-consuming demands for information under the US and UK Freedom of Information Acts. Governments and institutions need to provide tangible assistance for researchers facing such a burden.

The e-mail theft also highlights how difficult it can be for climate researchers to follow the canons of scientific openness, which require them to make public the data on which they base their conclusions. This is best done via open online archives, such as the ones maintained by the IPCC (www.ipcc-data.org) and the US National Climatic Data Center (www.ncdc.noaa.gov/oa/ncdc.html).

\section{Tricky business}

But for much crucial information the reality is very different. Researchers are barred from publicly releasing meteorological data from many countries owing to contractual restrictions. Moreover, in countries such as Germany, France and the United Kingdom, the national meteorological services will provide data sets only when researchers specifically request them, and only after a significant delay. The lack of standard formats can also make it hard to compare and integrate data from different sources. Every aspect of this situation needs to change: if the current episode does not spur meteorological services to improve researchers' ease of access, governments should force them to do so.

The stolen e-mails have prompted queries about whether Nature will investigate some of the researchers' own papers. One e-mail talked of displaying the data using a 'trick' - slang for a clever (and legitimate) technique, but a word that denialists have used to accuse the researchers of fabricating their results. It is Nature's policy to
"The theft highlights the harassment that denialists inflict on some climate-change researchers." investigate such matters if there are substantive reasons for concern, but nothing we have seen so far in the e-mails qualifies.

The UEA responded too slowly to the eruption of coverage in the media, but deserves credit for now being publicly supportive of the integrity of its scientists while also holding an independent investigation of its researchers' compliance with Britain's freedom of information requirements (see http://go.nature.com/zRBXRP).

In the end, what the UEA e-mails really show is that scientists are human beings - and that unrelenting opposition to their work can goad them to the limits of tolerance, and tempt them to act in ways that undermine scientific values. Yet it is precisely in such circumstances that researchers should strive to act and communicate professionally, and make their data and methods available to others, lest they provide their worst critics with ammunition. After all, the pressures the UEA e-mailers experienced may be nothing compared with what will emerge as the United States debates a climate bill next year, and denialists use every means at their disposal to undermine trust in scientists and science. 